\title{
Correspondence
}

To the Editor:

\section{ADULT DIASTEMATOMYELIA}

We read with interest the case report by Dr. Russell and colleagues entitled "Adult Diastematomyelia" and note the resolution of their patient's symptoms following removal of the diastematomyelia bony septum.

We published a case report ${ }^{2}$ of an adult whose symptoms did not resolve following removal of the septum, who needed further surgery for removal of a sacral coccygeal cyst and release of tethered cord. In common with other congenital occult spinal dysraphic lesions, it is difficult to define anatomic, or other factors that might be critical in the pathogenesis of clinical manifestation of adult diastematomyelia, as discussed by Russell et al.' We would however, draw attention to the high incidence of multiple occult congenital anatomic lesions in the central nervous system, ${ }^{3}$ and hence the importance of "screening" the entire craniospinal axis when one congenital spinal dysraphic lesion is identified.

F.B. Maroun, M.D., FRCSC J.C. Jacob, M.D.

St. John's, Newfoundland

1. Russell NA, Benoit BG, Joaquin AJ, Fayez NA. Adult Diastematomyelia. Can J Neurol Sci 1994; 21: 72-74.

2. Maroun FB, Jacob JC, Mangan MA and Hardjasudarma M. Adult Diastematomyelia: A Complex Dysraphic State; Surg Neuro October 1982; 18(4): 289-294.

3. Emery JL, Lendon RG. Clinical implication of cord lesions in Neurospinal dysraphism. Dev. Med. Child Neurol. Supp 27: 1972: 45-51.
Reply from the authors:

We thank Dr. Maroun and Dr. Jacob for their interest in our paper. Their point, that multiple congenital anomalies of the spine may complicate any dysraphic state, is well taken. We have published a review of 45 cases of adult diastematomyelia and found that 18 of these patients had a total of 31 associated spinal anomalies.' We agree that consideration should be given to "screening" the whole craniospinal axis when one dysraphic lesion is encountered. The availability of magnetic resonance imaging today, makes this a relatively easy task.

NA Russell, M.D., FRCSC

BG Benoit, M.D., FRCSC

AG Joaguin, M.D., FRCSC

NAI Faye: M.D.

1. Russell NA, Benoit BG, Joaquin AJ. Diastematomyelia in Adults. A Review. Pediatr Neurosurg 1990-91: 252-257. 